\title{
Fetal thrombotic vasculopathy: A case report and literature review
}

\author{
Ana Berquo Peleja ${ }^{1 *}$, Silvio Martinelli², Renata Lopes Ribeiro ${ }^{3}$, Roberto Eduardo Bittar ${ }^{4}$, Regina Schultz ${ }^{5}$, \\ Rossana Pulcineli Vieira Francisco 6 \\ ${ }^{1} \mathrm{MD}$ - Resident Physician in Obstetrics and Gynecology, Hospital das Clínicas, Faculdade de Medicina, Universidade de São Paulo (HC-FMUSP), São Paulo, SP, Brazil \\ ${ }^{2} \mathrm{PhD}$ in Science (Obstetrics and Gynecology) from FMUSP. Assistant Physician, Department of Obstetrics, FMUSP, São Paulo, SP, Brazil \\ ${ }^{3} \mathrm{MSc}$ in Obstetrics from FMUSP. Assistant Physician, Department of Obstetrics, FMUSP, São Paulo, SP, Brazil \\ ${ }^{4} \mathrm{PhD}$ and Habilitation (BR: Livre-docência) in Obstetrics and Gynecology from FMUSP. Associate Professor, Division of Obstetrics, Department of Obstetrics and Gynecology, FMUSP, São Paulo, SP, Brazil \\ ${ }^{5}$ PhD in Pathology from Universitat UIm, Germany. Assistant Physician, Division of Pathological Anatomy, Department of Pathology, FMUSP, São Paulo, SP, Brazil \\ ${ }^{6} \mathrm{PhD}$ in Medicine (Obstetrics and Gynecology) from FMUSP. Associate Professor, Division of Obstetrics, Department of Obstetrics and Gynecology, FMUSP, São Paulo, SP, Brazi
}

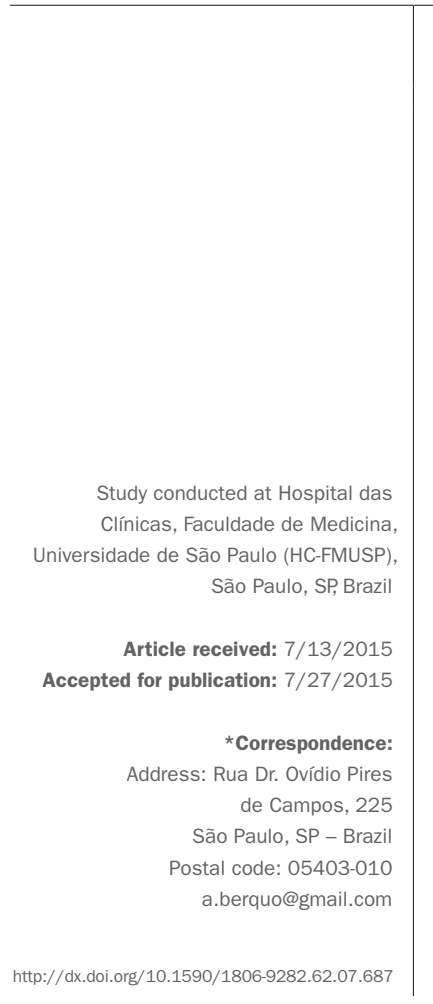

\section{SUMMARY}

Introduction: Fetal thrombotic vasculopathy is a recently described placental alteration with varying degrees of involvement and often associated with adverse perinatal outcomes. The diagnosis is made histologically and therefore is postnatal, which makes it a challenge in clinical practice.

Method: Case report and review of literature on the subject.

Results: The present case refers to a pregnant woman presenting fetal growth restriction, with poor obstetrical past, and sent late to our service. Even with weekly assessments of fetal vitality (fetal biophysical profile and Doppler velocimetry) and prenatal care, the patient progressed with fetal death at 36 weeks and 1 day. There was no association with inherited and acquired thrombophilia. Pathological examination of the placenta revealed fetal thrombotic vasculopathy. Conclusion: The fetal thrombotic vasculopathy may be associated with adverse perinatal outcomes including fetal death, but much remains to be studied regarding its pathogenesis. Diagnosis during pregnancy is not possible and there is still no proven treatment for this condition. Future studies are needed so that strategies can be developed to minimize the impact of fetal thrombotic vasculopathy.

Keywords: fetal death, placental diseases, fetal growth restriction.

\section{INTRODUCTION}

Fetal thrombotic vasculopathy (FTV) is a placental change described by Redline and Pappin in 1995 that encompasses several pathological findings in fetal placental circulation: fibrinoid vasculitis, avascular villi, hemorrhagic endovasculitis and thrombi in vessels, chorionic trunk or villi. ${ }^{1}$ These lesions limit perfusion of villi distal to the occlusion resulting in stromal-vascular karyorrhexis and avascular villi., ${ }^{2}, 12$

Even with a variety of possible clinical manifestations, FTV can remain asymptomatic until birth, induce fetal growth restriction (FGR) or cause fetal death when there is massive placental involvement or damage to the cord. To date, no specific sonographic criteria are reliable enough for the diagnosis of prenatal FTV. It can, however, be suspected in cases of FGR, Doppler changes such as zero or reverse diastole, and a non-reassuring intrapartum cardiotocography. ${ }^{3}$
The objective of this study is to report a case of FTV and present a literature review on the topic.

\section{Method}

Our article presents a case report of FTV with adverse perinatal outcome admitted to our service.

\section{Results}

A 40-year old pregnant woman, 5G2Pn2A, referred to our service at 33 weeks and 4 days with a diagnosis of FGR obtained by ultrasonography performed at 31 weeks and 2 days (estimated weight 1,400 g, Hadlock chart $7^{\text {th }}$ percentile). In previous obstetrical ultrasounds, performed at 23, 27, and 29 weeks, the estimated fetal weight was within the normal range for gestational age. The patient brought the result of a non-invasive test (whole blood) for assessment of fetal trisomy, which showed normal 
fetal karyotype at 12 weeks, and morphological ultrasound performed in the second trimester of pregnancy with no evidence of fetal malformations.

At the first consultation in our service, she was taking enoxaparin $40 \mathrm{mg}$ once daily and acetylsalicylic acid (ASA) $100 \mathrm{mg}$ daily, starting 15 days before.

Family history included a brother with heart disease and chronic hypertension, and a grandfather with diabetes mellitus. She did not have comorbidities and her blood pressure showed no alterations in the current pregnancy. The first and third pregnancies resulted in fetal death at 22 to 28 weeks, respectively. In the first pregnancy, the patient reports increased blood pressure. The second and fourth pregnancies progressed to abortion, at 7 and 8 weeks, respectively, and the patient underwent curettage on both occasions. A difference in the current pregnancy is that the baby's father is not the same.

Pathologic examination of the placenta in the third gestation revealed multiple placental infarcts and intervillous fibrin deposition; umbilical cord and chorio-amniotic membranes were unchanged.

At her first visit, we chose to continue treatment with ASA and stop enoxaparin. Obstetric ultrasounds were scheduled every two weeks and fetal vitality tests (biophysical profile and Doppler), on a weekly basis. Delivery was scheduled at 37 weeks.

Subsequent ultrasound scans performed at 33 and 35 weeks showed estimated fetal weight of $1,829 \mathrm{~g}$ (11 percentile) and 2,266g (11 percentile), respectively, thus a fetus with borderline growth restriction. Fetal vitality assessments at 33,34 , and 35 weeks did not demonstrate changes in fetal biophysical profile, umbilical artery or middle cerebral artery Doppler velocimetry at those occasions.

On the day of a new evaluation of fetal vitality, scheduled at a gestational age of 36 weeks and 1 day, fetal death was confirmed. The patient was hospitalized for cervical preparation with misoprostol and subsequent induction of labor with oxytocin for resolution of pregnancy.

Fetal necropsy revealed antenatal anoxia, generalized visceral congestion, amniotic fluid aspiration, and absence of fetal anomalies. It was a female fetus weighing $1,900 \mathrm{~g}$. The placenta had an oval shape and weighed $310 \mathrm{~g}$. The pathological study of the placenta revealed FTV with mural thrombosis of the chorionic and intraplacental arteries, amnion nodosum, and presence of large amounts of horny scales dissecting the amnion, forming a cystic cavity between amnion and chorion (Figures 1, 2, 3).

Thrombophilia tests were performed during hospital stay and after 2 months of hospital discharge, and only

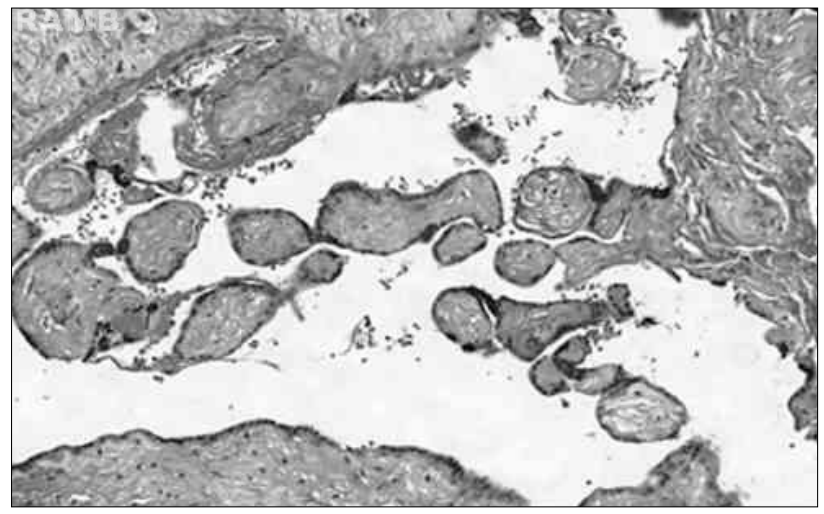

FIGURE 1 Histological section of placenta with groups of avascular villi (HE, 200x).

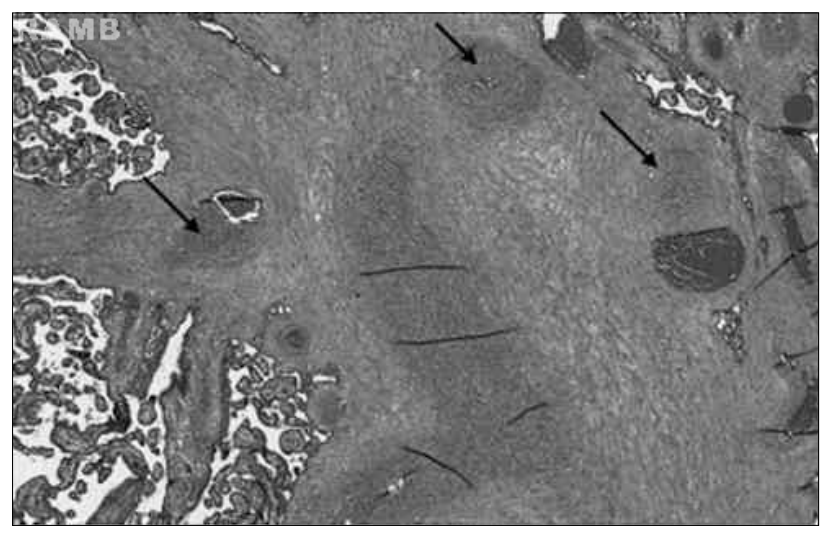

FIGURE 2 Histological section of placenta with arteries from villous trunks with thickening of the muscle wall and narrowing of the vascular lumen (arrows) (HE, 100x).

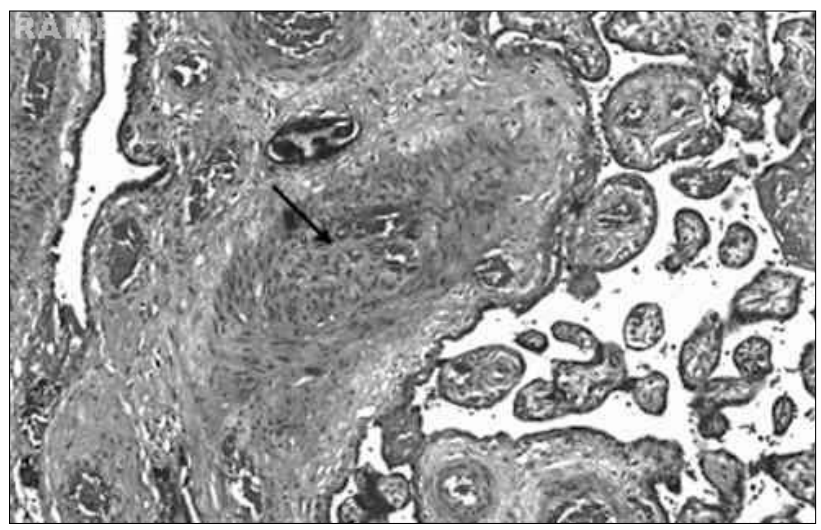

FIGURE 3 Histological section of placenta with artery from villous trunk showing occlusive thrombosis and luminal revascularization (arrow) (HE, 400x). 
a mutation of the methylenetetrahydrofolate reductase (MTHFR) enzyme in homozygous form was found. Other tests, including antiphospholipid syndrome (APS), antithrombin, homocysteine, $\mathrm{S}$ and $\mathrm{C}$ protein, Factor $\mathrm{V}$ Leiden mutation, and prothrombin gene mutation, showed values within the normal range.

\section{Discussion}

This case demonstrates the difficulty in the management of certain patients with FGR, especially when there is an adverse obstetrical past. The thrombophilia tests showed no significant changes, even after 2 months of stillbirth. The fetal vitality tests (biophysical profile and Doppler assessment of umbilical artery, middle cerebral artery, and ductus venosus) had normal values and were repeated weekly. Fetal death occurred 6 days before the scheduled date for resolution of pregnancy. The estimated fetal weight was at the limit of what we consider small for gestational age ( $10^{\text {th }}$ percentile). There are no sonographic criteria that might suggest FTV, which was identified only in the pathological examination of the placenta.

It is believed that the etiology of FTV is varied and complex, so that it can be summarized by changes in Virchow's triad: endothelial injury, hemodynamic abnormalities such as stasis or turbulence, and hypercoagulability. Thrombi found at the chorionic bed may lead to endothelial damage as a result of intense fetal acute inflammatory response, as in the case of chorioamnionitis. Factors related to the umbilical cord, including true knots and marginal or membrane insertions can also result in the formation of thrombi. ${ }^{5}$ Last, hypercoagulable states due to fetal or maternal thrombophilia have also been associated with FTV. ${ }^{4,11}$ Loh et al. ${ }^{4}$ report a case of fetal myeloproliferative disease, which resulted in hypercoagulable state and consequent FTV.

The Pediatric Pathology Society has proposed criteria for severe FTV classification: two or more foci of 15 or more avascular villi or villous stromal-vascular karyorrhexis. ${ }^{2}$ Such classification was studied by Chisholm et al. ${ }^{6}$ in a retrospective cohort of 139 cases, in which 67 cases with severe FTV large vessels were associated with preeclampsia, birth by fetal indication, lower placental weight, umbilical cord abnormalities, and small for gestational age fetus. In the cases that were not classified as severe, the results were similar to those without FTV. In addition, a possible association between severe FTV and neurological damage was suggested.

In a retrospective cohort study, Saleemuddin et al. ${ }^{7}$ studied placentas with $(\mathrm{n}=113)$ and without $(\mathrm{n}=216)$ a diagnosis of FTV and found an increase in the rate of fetal death, FGR, oligohidramnia, and a frequency nearly six times higher of fetal cardiac anomalies. Other fetal abnormalities have been reported in association with FTV. Lian et al. ${ }^{9}$ describe a case of congenital intestinal atresia, possibly due to FTV, and Ernst et al. ${ }^{1}$ report three cases of severe perinatal liver disease. As for neurological disorders after birth, the studies differ in respect to FTV as a causal factor. Mcdonald et al., in a retrospective cohort of 93 cases, found a relationship between FTV and the occurrence of neonatal encephalopathy. In a more recent study, Lepais et al., ${ }^{3}$ through a retrospective cohort analysis of 54 placentas and monitoring of newborns for 3 years, found an association between FTV and pregnancy-induced hypertension (PIH), FGR (5.4 times higher), perinatal death and early neonatal death, in addition to a greater need for caesarean sections and emergency deliveries. There was also a higher number of thromboembolic events during the follow-up of these children, while other abnormalities such as brain or cardiac impairment, or the presence of malformations, were not related to this change. Despite a higher incidence of developmental delay in the group with FTV, this finding was not statistically significant.

Magnetti et al. ${ }^{10}$ propose that the placenta of fetuses with perinatal thromboembolic events should be examined. Leistra-Leistra et al., in turn, found no correlation between the occurrence of fetal thromboembolism and FTV or thrombophilia and FTV.

\section{Conclusion}

FTV may be related to the occurrence of adverse perinatal outcomes, including FGR and fetal death, as described in the present case. The fact that the diagnosis is only possible in the postnatal period (pathological examination) makes FTV a major medical challenge, since irreversible fetal damage may have already been caused.

In many reports, there is no association with thrombophilia, as in this case. The presence of MTHFR mutation, but with normal homocysteine, is not consistent with the unfavorable progression of this pregnancy.

Apart from the borderline FGR (near the $10^{\text {th }}$ percentile for gestational age), there were no other relevant data that indicate a need to anticipate delivery. The outcome shown here is one of many possible in cases of FTV.

As a relatively recent abnormality, little is known about the pathogenesis, early detection and suspicion, and especially effective measures to change the unfavorable perinatal outcome. New criteria for diagnosis are highly desirable so that preventive measures can be taken during prenatal care. This is the desire of all those who deal with high-risk pregnancies. 


\section{Resumo}

Vasculopatia trombótica fetal: relato de caso e revisão da literatura

Introdução: a vasculopatia trombótica fetal é uma alteração placentária recentemente descrita, com espectro variado de acometimento e, muitas vezes, associada a resultado perinatal adverso. Trata-se de diagnóstico histopatológico e, portanto, pós-natal, o que a torna um desafio para a prática clínica.

Método: apresentação de um relato de caso e revisão da literatura.

Resultados: o caso apresentado é de uma gestante com restrição do crescimento fetal, encaminhada tardiamente ao serviço, com histórico obstétrico ruim. Apesar da avaliação semanal da vitalidade fetal (perfil biofísico fetal e dopplervelocimetria) e dos cuidados pré-natais, o caso evoluiu a óbito fetal com 36 semanas e 1 dia. Não houve associação com trombofilias hereditárias e adquiridas. O anatomopatológico da placenta revelou vasculopatia trombótica fetal.

Conclusão: sabe-se que a vasculopatia trombótica fetal pode estar associada a resultado perinatal adverso, incluindo óbito fetal. Ainda há muito a ser estudado acerca de sua etiopatogenia. Não é possível o diagnóstico durante a gestação e não existe ainda qualquer tratamento comprovado para essa condição. Estudos futuros são necessários para que estratégias que minimizem o impacto da vasculopatia trombótica fetal sejam desenvolvidas.
Palavras-chave: morte fetal, doenças placentárias, restrição do crescimento fetal.

\section{References}

1. Ernst LM, Grossman AB, Ruchelli ED. Familial perinatal liver disease and fetal thrombotic vasculopathy. Pediatr Dev Pathol. 2008; 11(2):160-3.

2. Leistra-Leistra MJ, Timmer A, van Spronsen FJ, Geven WB, van de Meer J, Erwich JJ. Fetal thrombotic vasculopathy in the placenta: a thrombophilic connection between pregnancy complications and neonatal thrombosis? Placenta. 2004; 25(Suppl A):S102-5.

3. Lepais L, Gaillot-durand L, Boutitie F, Lebreton F, Buf R, Huissoud C, et al. Fetal thrombotic vasculopathy is associated with thromboembolic events and adverse perinatal outcome but not with neurologic complications: a retrospective cohort study of 54 cases with a 3-year follow-up of children. Placenta. 2014; 35(8):611-7.

4. Loh TJZ, Lian DWQ, Iyer P, Lam JCM, Kuick CH, Aung ACL, et al. Congenital GATA1-mutated myeloproliferative disorder in trisomy 21 complicated by placental fetal thrombotic vasculopathy. Hum Pathol. 2014; 45(11):2364-7.

5. Taweevisit M, Thorner PS. Massive fetal thrombotic vasculopathy associated with excessively long umbilical cord and fetal demise: case report and literature review. Pediatr Dev Pathol. 2010; 13(2):112-5.

6. Chisholm KM, Heerema-McKenney A. Fetal thrombotic vasculopathy: significance in liveborn children using proposed society for pediatric pathology diagnostic criteria. Am J Surg Pathol. 2015; 39(2):274-80.

7. Saleemuddin A, Tantbirojn P, Sirois K, Crum CP, Boyd TK, Tworoger S, et al. Obstetric and perinatal complications in placentas with fetal thrombotic vasculopathy. Pediatr Dev Pathol. 2010; 13(6):459-64

8. Mcdonald D, Kelehan P, McMenamin JB, Gorman WA, Madden D, Tobbia IN, et al. Placental fetal thrombotic vasculopathy is associated with neonatal encephalopathy*1. Hum Pathol. 2004; 35(7):875-80.

9. Lian DW, Lam JC, Aung AC, Li FX, Chang KT. Intestinal atresia occurring in association with placental fetal thrombotic vasculopathy: a case report with literature review. Pediatr Dev Pathol. 2013; 16(1):28-31.

10. Magnetti F, Bagna R, Botta G, Viano A, Dorati G, Raia M, et al. Fetal thrombotic vasculopathy and perinatal thrombosis: should all placentas be examined? Am J Perinatol. 2014; 31(8):695-700.

11. Stanek J, Sheridan RM, Le LD, Crombleholme TM. Placental fetal thrombotic vasculopathy in severe congenital anomalies prompting EXIT procedure. Placenta. 2011; 32(5):373-9.

12. Redline RW. Fetal thrombotic vasculopathy: the clinical significance of extensive avascular villi. Human Pathol. 1995; 26(1):80-5. 